\title{
AlN/IDT/AIN/Sapphire SAW heterostructure for high-temperature applications
}

\author{
Ouarda Legrani ${ }^{1,2,3}$, Thierry Aubert ${ }^{2,3,4}$, Omar Elmazria ${ }^{1}$, Ausrine Bartasyte ${ }^{1}$, Pascal Nicolay ${ }^{5}$, Abdelkrim Talbi $^{6}$, \\ Pascal Boulet ${ }^{1}$, Jaafar Ghanbaja ${ }^{1}$, Denis Mangin ${ }^{1}$ \\ ${ }^{1}$ Institut Jean Lamour (IJL), UMR 7198 Université de Lorraine-CNRS, 54506 Vandoeuvre-lès-Nancy, France \\ ${ }^{2}$ LMOPS, CentraleSupélec, Université de Paris-Saclay, 57070 Metz, France \\ ${ }^{3}$ LMOPS, CentraleSupélec, Université de Lorraine, 57070 Metz, France \\ ${ }^{4}$ Laboratoire SYMME, Université Savoie Mont Blanc, 74944 Annecy-le-Vieux, France \\ ${ }^{5}$ Carinthian Tech Research (CTR AG), 9524 Villach/St Magdalen, Austria \\ ${ }^{6}$ LIA LEMAC/LICS - IEMN, UMR 8520, EC Lille-CNRS, 59652 Villeneuve d'Ascq, France.
}

\begin{abstract}
Recent studies have evidenced that Pt/AIN/Sapphire SAW devices are promising for high-temperature high-frequency applications. However, they cannot be used above $700^{\circ} \mathrm{C}$ in air atmosphere as the $\mathrm{Pt}$ interdigital transducers (IDTs) agglomerate and the AIN layer oxidizes in such conditions. In this paper, we explore the possibility to use an AIN protective overlayer to concurrently hinder these phenomena. To do so, AIN/IDT/AIN/Sapphire heterostructures undergo successive annealing steps from $800^{\circ} \mathrm{C}$ to $1000^{\circ} \mathrm{C}$ in air atmosphere. The impact of each step on the morphology, microstructure and phase composition of AIN and Pt films is evaluated by means of optical microscopy, scanning and transmission electron microscopy (SEM \& TEM), X-ray diffraction (XRD) and secondary ion mass spectroscopy (SIMS). Finally, acoustical performance at room temperature of both protected and unprotected SAW devices are compared, as well as the effects of annealing on these performance. These investigations show that the use of an overlayer is one possible solution to strongly hinder the Pt IDTs agglomeration up to $1000^{\circ} \mathrm{C}$. Moreover, AIN/IDT/AIN/Sapphire SAW heterostructures show promising performances in terms of stability up to $800^{\circ} \mathrm{C}$. At higher temperatures, the oxidation of AlN is more intense and makes it inappropriate to be used as a protective layer.
\end{abstract}

Keywords- AlN ; high-temperature ; $S A W$; protective layer ; platinum IDTs

\section{INTRODUCTION}

Because they can be remotely interrogated while being passive, surface acoustic wave (SAW) devices have been intensively studied in the last 15 years to achieve wireless SAW sensors for a variety of industrial applications taking place between $200^{\circ} \mathrm{C}$ and $1000^{\circ} \mathrm{C}$ that cannot be addressed by wired sensors. In this context, one of the main challenges to overcome concerns the choice of the constitutive materials. Regarding the piezoelectric substrate, the most promising results were obtained so far with langasite $\left(\mathrm{La}_{3} \mathrm{Ga}_{5} \mathrm{SiO}_{14}\right.$, LGS). In particular, Pereira da Cunha et al. operated an LGS-based SAW device for more than 5 months at $800^{\circ} \mathrm{C}$ [1] while Aubert et al. measured a signal coming from a similar device up to $1140^{\circ} \mathrm{C}$ [2]. However, LGS is limited by relatively high propagation losses, especially at high frequencies, which confines the operating frequency of high-temperature wireless
LGS-devices to the several hundred megahertz range [3-4]. Moreover, as many oxides, LGS suffers from $\mathrm{O}$ losses (accompanied by Ga ones) when placed at high temperature in low-oxygen environment [2,5]. Finally, LGS even shows weaknesses in air atmosphere when the temperature comes close to $1000^{\circ} \mathrm{C}$. In such conditions, local defects appear on the substrate surface, notably modifying the performance of SAW devices [6]. Thus, it is necessary to find alternatives to LGS for specific applications. Recent studies have shown that AlN/Sapphire is a promising piezoelectric structure for hightemperature SAW applications [7-12], even in the GHz-range [13-14]. However, the oxidation of AIN prohibits the use of this structure above $700^{\circ} \mathrm{C}$ in air [11]. Atmospheres containing much lower levels of oxygen can also be a problem at higher temperatures [12]. Consequently, AlN-based devices may only be considered for such applications if the AlN layer is protected from oxygen.

Concerning IDTs, Pt-based electrodes are commonly used for high-temperature SAW applications because of the noble character of Pt. However, $100-\mathrm{nm}$ thick $\mathrm{Pt}$ thin films agglomerate at temperatures higher than $700^{\circ} \mathrm{C}[1,15]$. Da Cunha et al. significantly increased the performance of Ptbased IDTs by the use of Pt-Rh alloys and Pt-Rh- $\mathrm{ZrO}_{2}$ nanocomposites [1]. This strategy consists in adding impurities in the $\mathrm{Pt}$ film to hinder diffusion phenomena that drive agglomeration. The lifetime of pure $\mathrm{Pt}$ electrodes can also be increased by the use of a protective overlayer. Firebaugh et al. found that the lifetime of Pt electrodes at $900^{\circ} \mathrm{C}$ is multiplied by a factor 6 when protected by a 300 nm-thick alumina overlayer [16]. Da Cunha et al. observed a significant decrease of the agglomeration kinetics of Pt-based IDTs using an ultrathin SiAlON protective layer [1]. The protective overlayer plays at least two roles. First, it helps to mechanically fasten the Pt nanocristallites constituting the IDTs. Secondly, it acts as a useful barrier against oxygen, as it was shown that oxygen plays a major role in the agglomeration mechanisms [15-16].

Consequently, the use of a protective overlayer in the case of Pt/AlN/Sapphire SAW devices would have two benefits: on one hand, protect the AIN layer from oxidation, and hinder $\mathrm{Pt}$ IDTs agglomeration on the other hand. 
The aim of the present study is to determine the potential of AIN itself as a protective layer. To do so, AIN/IDT/AIN/Sapphire heterostructures underwent a hightemperature cycle made of successive annealing steps at temperatures ranging from $800^{\circ} \mathrm{C}$ to $1000^{\circ} \mathrm{C}$ in air atmosphere. The effects of high temperature exposure on the morphology, microstructure, phase composition and acoustical performance of the samples are then studied and discussed.

\section{EXPERIMENTAL PROCEDURE}

The initial bilayer structure was composed by a $1 \mu \mathrm{m}$-thick smooth (002) AlN film $\left(\mathrm{R}_{\mathrm{rms}}=8 \AA\right)$, hetero-epitaxied on $\mathrm{C}$ plane sapphire substrate by MOCVD technique (supplied by MTI Corp., Richmond, CA). 10 nm-thick tantalum as an adhesion layer and $120 \mathrm{~nm}$-thick platinum films as electrodes were then deposited by sputtering method. IDTs were structured by a standard photolithography process and ion beam etching. The spatial period of the IDTs was $16 \mu \mathrm{m}\left(\mathrm{kh}_{\mathrm{AIN}}\right.$ $=0.39$ ). The IDTs center spacing, acoustic aperture, and finger width to space ratio were $65 \lambda, 27 \lambda$, and $1: 1$, respectively. The SAW propagation path was along the $X$ direction of the sapphire substrate. A1 $\mu \mathrm{m}$-thick AlN protective overlayer was finally deposited by RF magnetron sputtering. The pressure in the chamber was $2.10^{-1} \mathrm{~Pa}\left(1: 4\right.$ of $\mathrm{N}_{2}$ :Ar) and the power injected in the plasma was $170 \mathrm{~W}$. The distance target-substrate was fixed at $80 \mathrm{~mm}$ and the temperature substrate was $400^{\circ} \mathrm{C}$. These parameters were used in order to obtain a crystallized coriented AlN protective layer. Such a microstructure was aimed for two reasons. First, crystallized protective layers are preferred to amorphous ones as the latter could contain porosity that makes the oxygen diffusion easier. Secondly, the use of a c-oriented overlayer results in the increase of the piezoelectric AlN relative thickness $(\mathrm{h} / \lambda)$, and thus in a potential reinforcement of the heterostructure piezoelectric properties. During sputtering, the pads of IDTs were masked in order to keep an access for electrical measurements thereafter. Thus, as illustrated in Fig. 1, the pads were not protected by the AlN overlayer. To increase the lifetime of the connection pads regarding agglomeration phenomena, the thickness of the IDTs was increased in these areas by a second deposition of Ta (10 $\mathrm{nm})-\mathrm{Pt}(120 \mathrm{~nm})$ layer [16].

Some protected and unprotected devices were electrically characterized up to $600^{\circ} \mathrm{C}$ in air atmosphere using a network analyzer (PNA 5230a, Agilent Technologies Inc., Santa Clara, $\mathrm{CA}$ ) and an RF prober station (S-1160, Signatone Corp., Gilroy, CA) equipped with an S-1060 series Signatone thermal chuck to control temperature between $20^{\circ} \mathrm{C}$ and $600^{\circ} \mathrm{C}$. To withstand high temperature, the used RF probes ( $Z$ Probe SussMicrotech) were modified by adding a water-cooling system.

The protected and unprotected devices were annealed in air in six successive steps: $2 \mathrm{~h}$ at $800^{\circ} \mathrm{C}\left(1^{\text {st }}\right.$ step $), 10 \mathrm{~h}$ at $800^{\circ} \mathrm{C}\left(2^{\text {nd }}\right.$ step), $2 \mathrm{~h}$ at $900^{\circ} \mathrm{C}\left(3^{\text {rd }}\right.$ step $), 10 \mathrm{~h}$ at $900^{\circ} \mathrm{C}$ ( $4^{\text {th }}$ step $), 2 \mathrm{~h}$ at $1000^{\circ} \mathrm{C}\left(5^{\text {th }}\right.$ step $)$ and finally $10 \mathrm{~h}$ at $1000^{\circ} \mathrm{C}\left(6^{\text {th }}\right.$ step $)$. After each annealing step, the samples were cooled down to room temperature and the frequency response $S_{21}$ of the devices was measured with a network analyzer. The morphology of the $\mathrm{Pt}$ IDTs and the AIN overlayer were observed by optical microscopy and scanning electron microscopy (SEM - FEI XL30 S-FEG) respectively. Phase composition and microstructures were obtained by X-ray diffraction (XRD) in Bragg-Brentano geometry (Bruker D8 advance $-\mathrm{CuK}_{\alpha 1:} \lambda=$ $1.54056 \AA$ ) and transmission electronic microscopy (TEM FEI CM200). Chemical elements depth profiles were obtained by means of secondary ion mass spectroscopy (SIMS Cameca IMS-7F equipment).

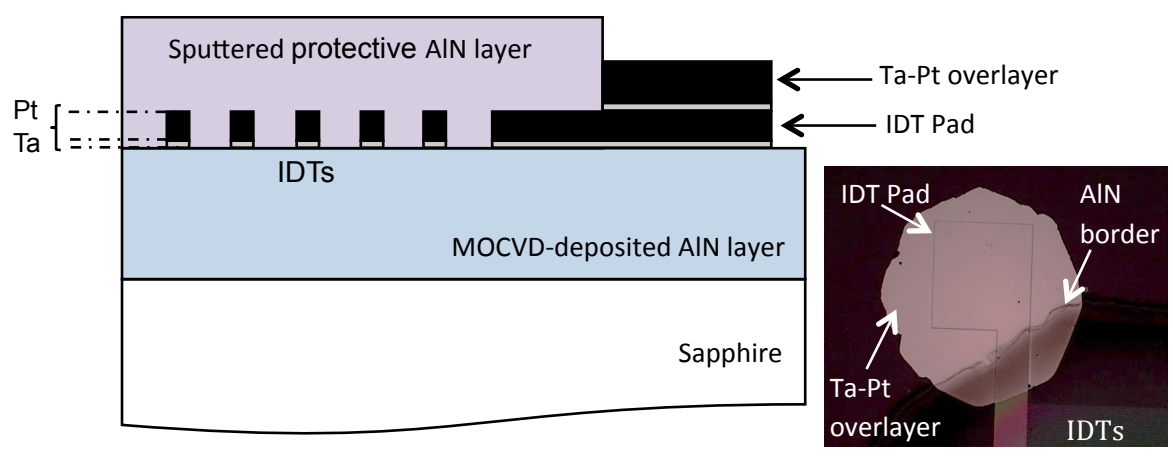

Figure 1. Profile schematics of the AIN/IDT/AIN/Sapphire heterostructure (left) and plan optical image of the IDT pad area (right). 


\section{RESULTS AND DISCUSSION}

One of the main results of this study is related to the capability of the AlN overlayer to hinder IDTs agglomeration. First signs of IDTs degradation are clearly visible after the fourth annealing step $\left(12 \mathrm{~h}\right.$ at $800^{\circ} \mathrm{C}+12 \mathrm{~h}$ at $\left.900^{\circ} \mathrm{C}\right)$ on unprotected devices (Fig.2 (a)). The density and size of delaminated areas grow up during the two last annealing steps at $1000^{\circ} \mathrm{C}$, while electrode fingers steadily agglomerates, so that the electrodes are totally damaged at the end of the whole annealing cycle. Regarding the protected AIN/IDT/AIN/sapphire heterostructures, no IDTs deterioration was observed after a complete cycle of high temperature annealing $\left(12 \mathrm{~h}\right.$ at $800^{\circ} \mathrm{C}+12 \mathrm{~h}$ at $900^{\circ} \mathrm{C}+12 \mathrm{~h}$ at $\left.1000^{\circ} \mathrm{C}\right)$ : no delamination and no agglomeration phenomena of platinum film occurred (Fig.2 (b)). This result highlights the effectiveness of AlN used as an overlayer, to enlarge the lifetime of pure Pt IDTs at high temperatures up to $1000^{\circ} \mathrm{C}$.

The evolution of the AlN overlayer morphology throughout the successive annealing steps can be seen on Fig. 2(c). The top AlN surface of the as-deposited samples shows well-defined nanograins. Except from blurrier grain boundaries, no major change in the morphology can be observed after the annealing steps at 800 and $900^{\circ} \mathrm{C}$. This granular morphology disappears during the $2 \mathrm{~h}$-long annealing step at $1000^{\circ} \mathrm{C}$. Regular grains are replaced by larger oblong structures and pores in between. The size of these structures and pores increases during the last annealing step at $1000^{\circ} \mathrm{C}$. The cross-sectional TEM images confirm these results, indicating that the microstructure of the AlN overlayer remains columnar after the four first annealing steps, to transform into the porous one during annealing at $1000^{\circ} \mathrm{C}$ (Fig. 2(d)).

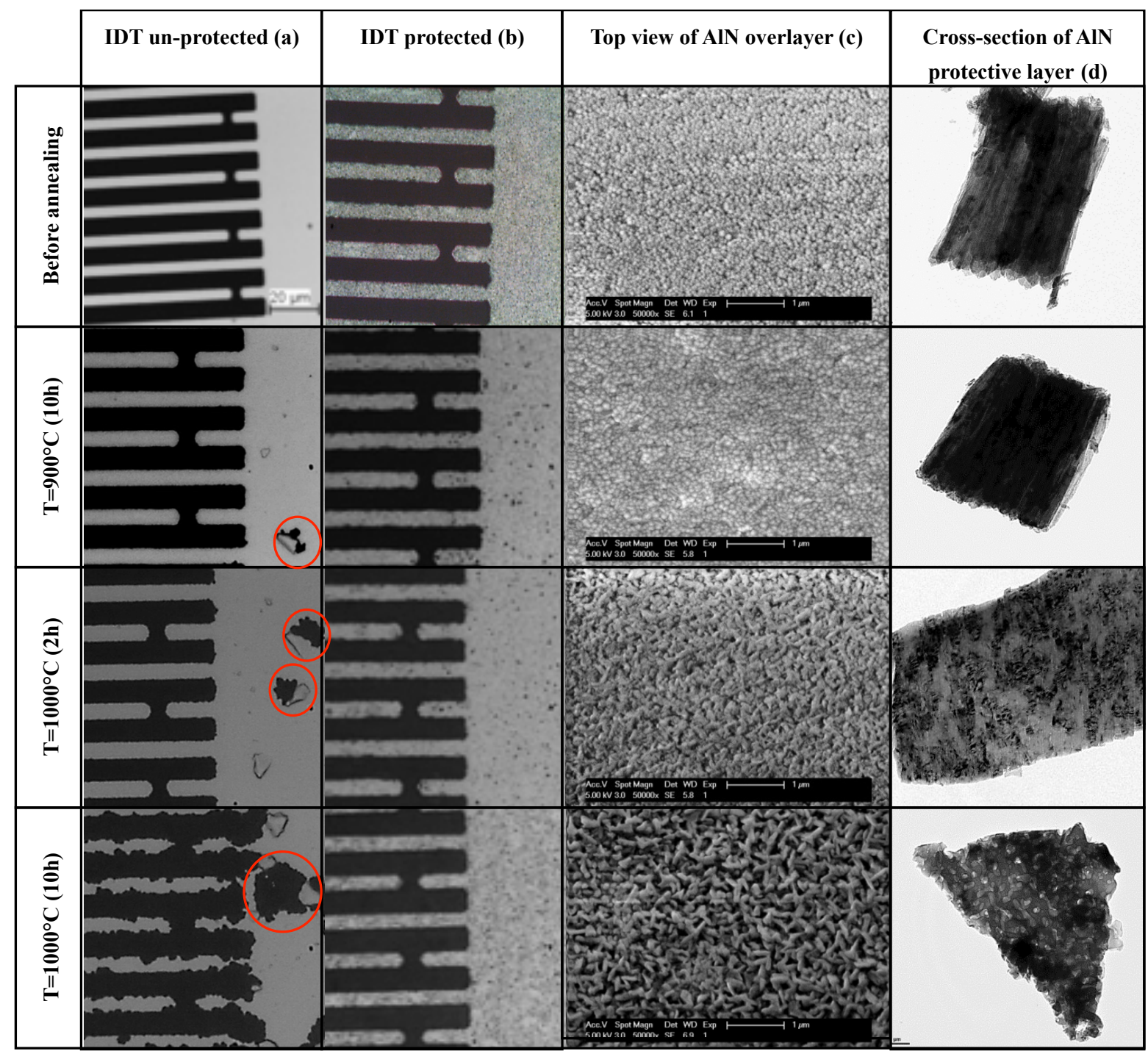

Figure 2. Optical images of unprotected IDTs (a) and AlN-protected ones (b), SEM images of the AlN overlayer surface (c), cross-sectional TEM images of the AlN protective layer (d): before annealing, after the $4^{\text {th }}\left(10 \mathrm{~h}\right.$ at $\left.900^{\circ} \mathrm{C}\right), 5^{\text {th }}\left(2 \mathrm{~h}\right.$ at $\left.1000^{\circ} \mathrm{C}\right)$ and $6^{\text {th }}\left(10 \mathrm{~h}\right.$ at $\left.1000^{\circ} \mathrm{C}\right)$ annealing steps. 
The $\theta / 2 \theta$ XRD spectrum of the non-annealed AlN/IDT/AIN/Sapphire points out that both AlN layers are highly (002)-textured (Fig. 3). One can also note the presence of a small peak at $2 \theta=37.8^{\circ}$ corresponding to the (110) $\alpha$ $\mathrm{Al}_{2} \mathrm{O}_{3}$ (sapphire) reflection, related to the presence of a native (crystallized) oxide layer at the surface of AIN inner layer as observed with SIMS as well (see further). Note that native oxide layers are generally amorphous [17]. However, in our case, it is likely that it crystallized during the AlN overlayer sputtering deposition thanks to the energy provided by this process to the surface atoms. No significant change in the XRD spectrum can be observed until the end of the $5^{\text {th }}$ annealing step $\left(2 \mathrm{~h}\right.$ at $\left.1000^{\circ} \mathrm{C}\right)$. The intensity of the $(002)$ and (004) AlN reflections decreases then dramatically during the last $10 \mathrm{~h}$-long annealing step at $1000^{\circ} \mathrm{C}$, while a couple of $\alpha$ $\mathrm{Al}_{2} \mathrm{O}_{3}$ peaks appear or get much stronger in the case of the (110) reflection. This result, together with the morphological and microstructural changes depicted on Fig. 2, indicates that the AlN overlayer oxidizes deeply at $1000^{\circ} \mathrm{C}$, the oblong structures revealed by SEM likely being $\alpha-\mathrm{Al}_{2} \mathrm{O}_{3}$ grains.

Clarifications about the oxidation process undergone by each AlN layer were then obtained by SIMS (Fig. 4). Indeed, the over- and inner AlN layers can be easily distinguished on SIMS depth profiles for two reasons. First, a native aluminum oxide film is present at the interface in between them. Moreover, the $\mathrm{O}$ level is higher in the sputtered top layer than in the inner layer deposited by MOCVD (Fig. 4(a)).

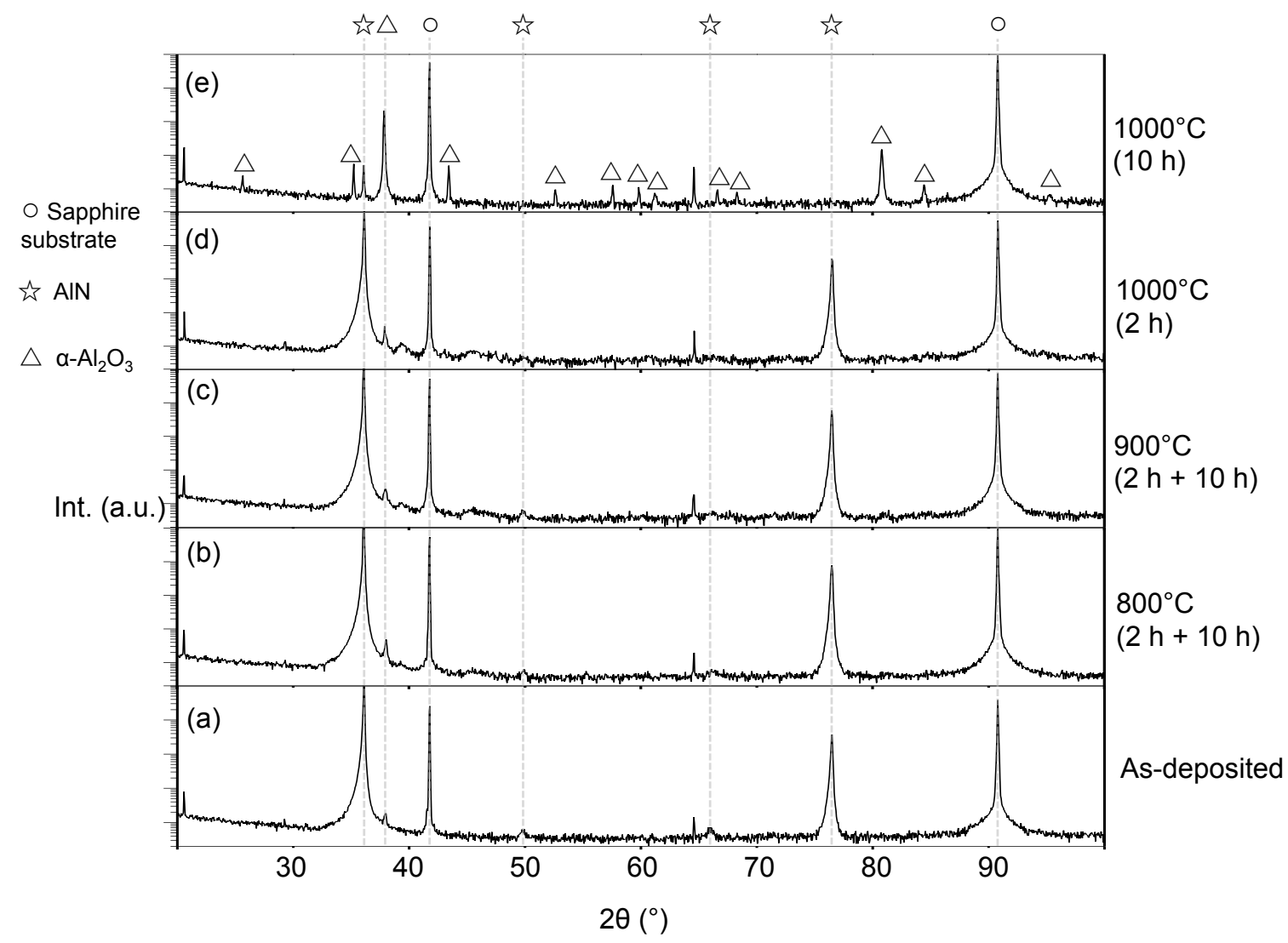

Figure 3. $\theta / 2 \theta \mathrm{XRD}$ spectra of the AIN/IDT/AIN/Sapphire heterostructure: before annealing (a), after the annealing steps at $800^{\circ} \mathrm{C}(\mathrm{b})$, after the annealing steps at $900^{\circ} \mathrm{C}(\mathrm{c})$, after the $2 \mathrm{~h}$-long annealing step at $1000^{\circ} \mathrm{C}(\mathrm{d})$, after the final $10 \mathrm{~h}$-long annealing step at $1000^{\circ} \mathrm{C}(\mathrm{e})$. 
(a) As-deposited

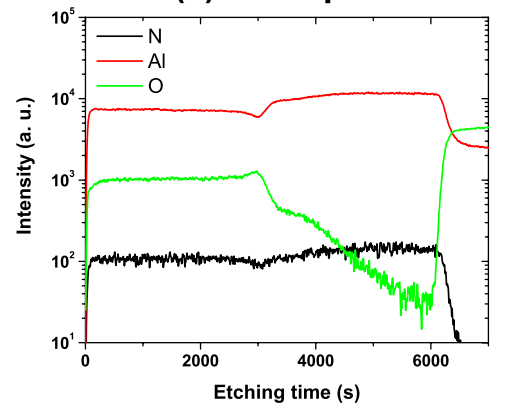

(b) $800^{\circ} \mathrm{C}(2 \mathrm{~h}+10 \mathrm{~h})$

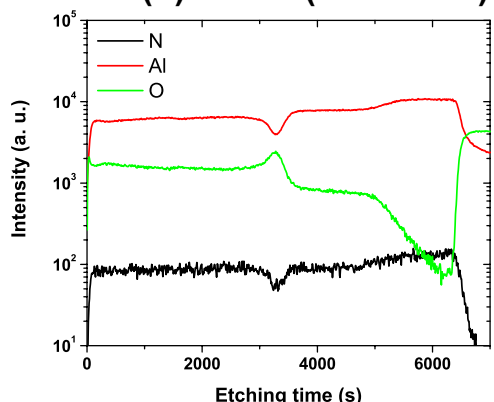

(c) $900^{\circ} \mathrm{C}(2 \mathrm{~h}+10 \mathrm{~h})$

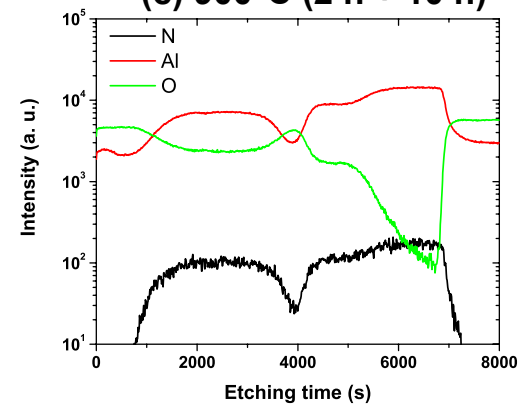

(d) $1000^{\circ} \mathrm{C}(2 \mathrm{~h})$

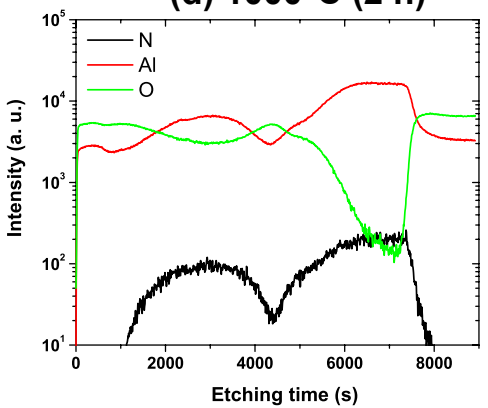

(e) $1000^{\circ} \mathrm{C}(10 \mathrm{~h})$

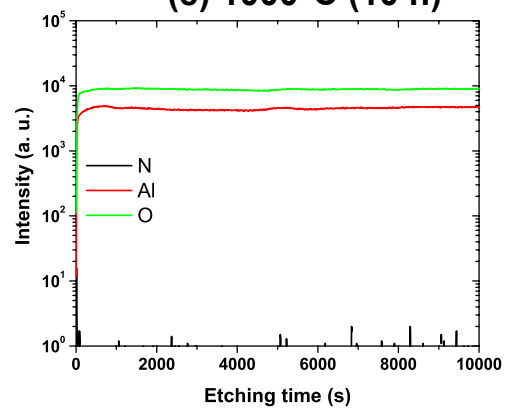

Figure 4. SIMS chemical depth profiles of the AlN/IDT/AIN/sapphire heterostructure: before annealing (a), after the annealing steps at $800^{\circ} \mathrm{C}(\mathrm{b})$, after the annealing steps at $900^{\circ} \mathrm{C}(\mathrm{c})$, after the $2 \mathrm{~h}$-long annealing step at $1000^{\circ} \mathrm{C}(\mathrm{d})$, after the final $10 \mathrm{~h}-$ long annealing step at $1000^{\circ} \mathrm{C}(\mathrm{e})$.

At first sight, no major change can be observed in the chemical depth profiles obtained after the annealing steps at $800^{\circ} \mathrm{C}$ (Fig. 4(b)). However, it is known that an oxide overlayer with a thickness of some tens of nanometers should form in these conditions [11]. The SIMS analysis performed in the frame of this study aimed at comparing the respective behavior regarding oxidation of both AIN layers throughout the whole annealing process. Thus, it was necessary to conduct this analysis from the surface to the substrate (which means a thickness of at least $2 \mu \mathrm{m}$ ). Consequently, the profiles obtained during the first seconds of the analysis, corresponding to the samples extreme surface, are not so accurate. However, a deeper inspection of the onset of the SIMS analysis conducted on the reference sample (Fig. 4(a)) and the one annealed for 12 hours at $800^{\circ} \mathrm{C}$ (Fig. 4(b)) shows that the O-signal increases faster (compared to Al- and N-signals) in the second case. We assume that this phenomenon is related to the presence of this very thin oxide overlayer.

Subsequent SIMS analyses reveal that the oxidation process of the AlN top layer becomes significant after the fourth annealing step $\left(10 \mathrm{~h}\right.$ at $\left.900^{\circ} \mathrm{C}\right)$ : the thickness of the oxide layer formed onto the surface of the AlN protective layer is roughly estimated to be about $200 \mathrm{~nm}$, which is consistent with the literature (Fig. 4(c)) [11]. After the next annealing step $\left(1000^{\circ} \mathrm{C}\right.$ for $2 \mathrm{~h}$ ), this thickness has increased by $100 \mathrm{~nm}$ (Fig. $4(d))$. Finally, when the annealing time at $1000^{\circ} \mathrm{C}$ was increased to $10 \mathrm{~h}$, the oxidation process accelerates dramatically, so that both AIN layers were almost completely oxidized, as expected regarding the XRD results (Fig. 4(e)).
According to the overall previous results, it seems that the oxidation mechanisms change when the temperature reaches $1000^{\circ} \mathrm{C}$. Up to $900^{\circ} \mathrm{C}$, a thin amorphous aluminium oxide layer forms on top of the AlN surface. The kinetics of this kind of oxidation is well known: the formed oxide overlayer acts as a diffusion barrier for the $\mathrm{O}_{2}$ molecules coming from the atmosphere, so that the oxidation kinetics slows down gradually as the oxide layer gets thicker [18]. A major change occurs at $1000^{\circ} \mathrm{C}$ with the apparition of pores inside the AlN layer. These pores make it easier for the atmospheric oxygen to diffuse and create new pores deeper inside the layer. This mechanism leads in fine to the complete oxidation of both AIN layers in a few hours. The apparition of pores is likely related to the successive heating-cooling steps undergone by the samples. Indeed, the mismatch between the thermal expansion coefficients (TCE) of $\alpha-\mathrm{Al}_{2} \mathrm{O}_{3}\left(7.3 \mathrm{ppm} . \mathrm{K}^{-1}\right)$ and $\mathrm{AlN}(5.3$ $\mathrm{ppm} . \mathrm{K}^{-1}$ ) results in tensile stress forming in the oxide layer during each cooling down, that leads to the formation of cracks and then pores [19].

Regarding experimental SAW measurements, the deposition of the AIN protective overlayer significantly decreased the room temperature performance of the devices. Indeed, one can observe that the insertion losses increased by $14 \mathrm{~dB}$, while the passband became significantly narrower (Fig. 5). 


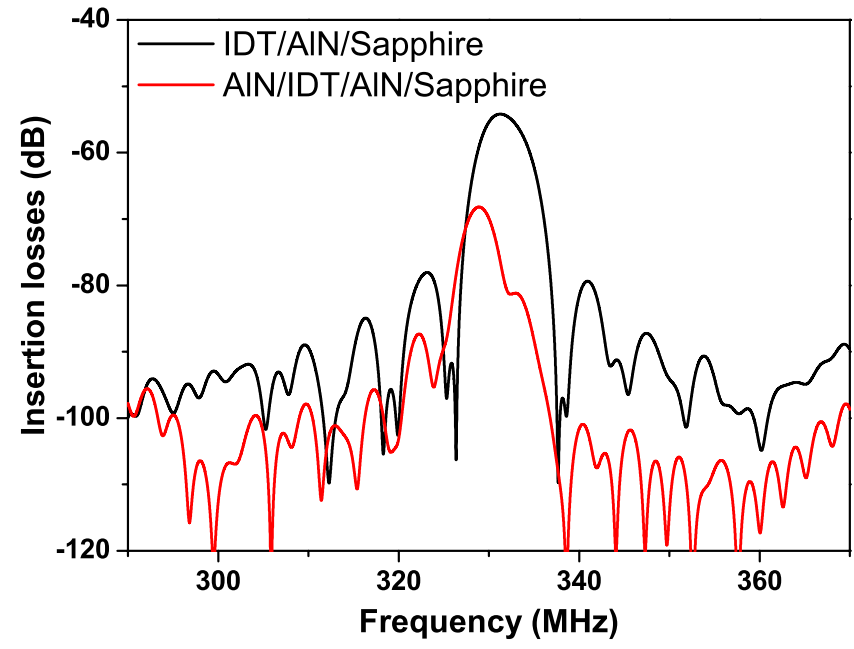

Figure 5. Experimental $\mathrm{S}_{21}$ frequency responses of unprotected and AlNprotected SAW devices at $25^{\circ} \mathrm{C}$

To understand this phenomenon, the evolution of the electromechanical coupling coefficient $\mathrm{K}^{2}$ of the structure with the thickness of the AlN overlayer was computed using the well-known Campbell and Jones method [20] and the material constants found in Ref. [21]. $\mathrm{K}^{2}$ initial value $(\mathrm{kh}=0.4$; without AlN overlayer) was found to be $0.06 \%$, which is in excellent agreement with former results from Tsubouchi et al. [21] and Caliendo [22]. Then, $\mathrm{K}^{2}$ steadily decreases to a minimum value of $0.03 \%$ when the AlN overlayer thickness reaches $1 \mu \mathrm{m}$ $\left(\mathrm{kh}_{\text {total }}=0.8\right)$, corresponding to the actual experimental value used in this study (Fig. 6). This result could explain the observed narrowing of the passband (Fig. 5). Beyond this thickness, $\mathrm{K}^{2}$ increases to retrieve the initial value when the AlN overlayer thickness reaches $3 \mu \mathrm{m}\left(\mathrm{kh}_{\text {total }}=1.5\right)$. Based on these calculations, it appears that the choice of the protective layer thickness was not appropriate from an electromechanical point of view. Note that this configuration (IDTs sandwiched between both AlN layers) gives higher $\mathrm{K}^{2}$ values (up to 0.58 $\%$ ) for large overall AlN relative thicknesses, compared with the configurations where the IDTs are above the AlN layers or in between the AIN layers and the sapphire substrate (Fig. 6).

Moreover, the experimental operating frequency shifted towards lower frequencies by $2.3 \mathrm{MHz}$ after the AlN overlayer growth (Fig. 5). Calculations using the Tsubouchi AlN material constants [21] cannot explain this decrease in the SAW velocity (Fig. 7). Obviously, the use of identical material constants set for both AIN layers is not relevant regarding the different growth methods. This is confirmed by SIMS measurements, which reveal that the sputtered AlN layer contains much more oxygen than the layer deposited by MOCVD (Fig. 4(a)). Carlotti et al. measured the elastic constants sets of sputtered AlN films containing different amounts of oxygen, showing that such AlN films become softer and softer when the oxygen content increases [23]. Regarding the epitaxial AIN inner layer, different elastic constants sets can be found in the literature. We performed simulations using two of these sets, from Tsubouchi et al. [21] and Deger et al. [24] (the latter being very close to AlN single crystals' set [25]). Carlotti's and Deger's elastic constants sets were completed with the AlN piezoelectric and dielectric constants coming from Ref. [21]. Calculations show that the observed qualitative behavior after the AlN overlayer deposition (i.e. a decrease in SAW velocity) can be retrieved using Carlotti's and Deger's constants sets (Fig. 7). Quantitatively, the computed evolution in velocity is $-16 \mathrm{~m} / \mathrm{s}$ whereas the observed experimental value is $-37 \mathrm{~m} / \mathrm{s}$. Note that the evolution of $\mathrm{K}^{2}$ (described hereinabove) is unchanged when Tsubouchi's elastic constants are replaced by Carlotti's and Deger's ones (not shown here).

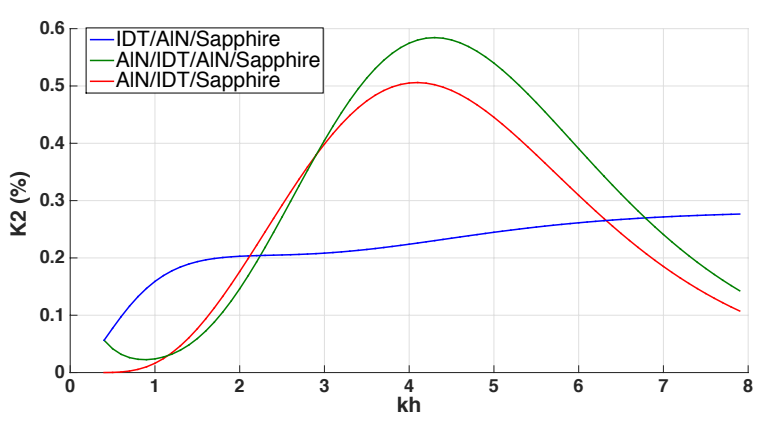

Figure 6. Computed $\mathrm{K}^{2}$ evolution with the total (AlN overlayer + AlN inner layer) AlN relative thickness $(\mathrm{kh})$. Calculations were performed using the Campbell \& Jones method and the Tsubouchi's material constants set [21]. Calculations start from a kh value of $0.04 \%$, corresponding to the initial situation (without AlN overlayer). Three configurations are taken into consideration, depending on the IDTs position: IDTs above the AIN layers (blue), IDTs between the AIN layers and the sapphire substrate (red), IDTs inbetween the AlN inner- and overlayer (green) as in the actual heterostructure.

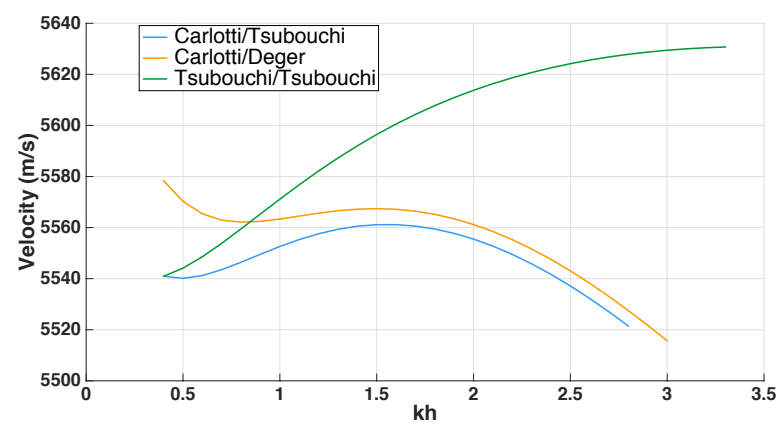

Figure 7. Computed SAW velocity evolution with the total (AIN overlayer + AlN inner layer) AlN relative thickness (kh) in the AlN/IDT/AIN/Sapphire heterostructure. Calculations were performed using the Campbell \& Jones method. Calculations start from a kh value of $0.04 \%$, corresponding to the initial situation (without AlN overlayer). First calculations were made using

Tsubouchi's material constants set [21] only. Then, Carlotti's material constants set [23] was used for the sputtered AlN overlayer and Deger's one [24] for the epitaxial inner layer. 
Both structures, with and without overlayer, exhibited a large and quasi-constant first-order temperature coefficient of frequency (TCF) close to $-80 \mathrm{ppm} /{ }^{\circ} \mathrm{C}$ in the temperature range from $20^{\circ} \mathrm{C}$ to $600^{\circ} \mathrm{C}$ (Fig. 8). The evolution of the $\mathrm{S}_{21}$ parameter of the protected structure throughout the annealing cycle is shown in Fig. 9. The first annealing step induced a slight decrease in the insertion losses (not shown) that can be related to the recrystallization of the Pt IDTs [15].

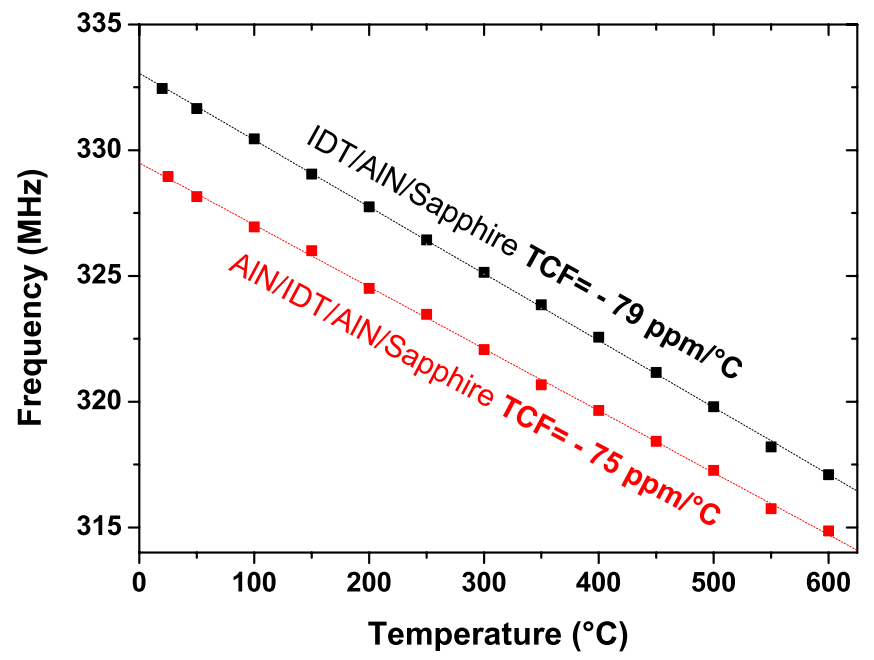

Figure 8. Frequency-temperature dependencies of the unprotected and AlNprotected SAW devices. Dashed lines correspond to the linear fit of this experimental data.

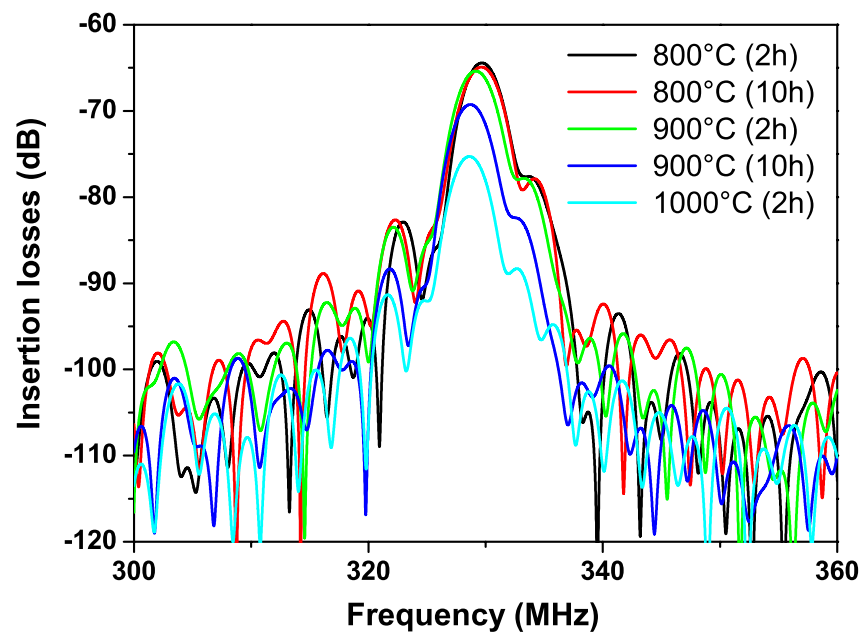

Figure 9. $\mathrm{S}_{21}$ frequency response at room temperature of the heterostructure after different annealing steps.
One can observe that the frequency response of the protected device hardly changed after the second annealing step $\left(10 \mathrm{~h}\right.$ more at $\left.800^{\circ} \mathrm{C}\right)$. This result is very promising. It shows that the use of an AlN protective layer could extend the stability range of AlN-based SAW devices up to $800^{\circ} \mathrm{C}$, in air atmosphere. This improvement is obviously related to the stabilization of the pure Pt IDTs, regarding agglomeration phenomena. It is also related to the fact that the SAW properties are not significantly affected by the very thin oxide overlayer forming at the surface of the AlN protective layer during oxidation at $800^{\circ} \mathrm{C}$. It will be necessary to check this result over long term annealing periods.

After the next annealing steps at $900^{\circ} \mathrm{C}$, the operating frequency shifts gradually towards lower frequencies, while IL increase by $5 \mathrm{~dB}$. These phenomena are likely related to the significant increase of the oxide overlayer thickness, as shown by SIMS measurements. Finally, as expected regarding the material analyzes presented hereinabove, the deterioration of the device performance accelerates at $1000^{\circ} \mathrm{C}$, leading to the signal loss after the final annealing treatment of $10 \mathrm{~h}$ at $1000^{\circ} \mathrm{C}$. It has to be noted that the SAW measurements confirm that the unprotected structures deteriorate much quicker than the protected ones (Fig. 10). As an illustration, after the fifth annealing step $\left(1000^{\circ} \mathrm{C}\right.$ for $\left.2 \mathrm{~h}\right)$, the IL increase was only $10 \mathrm{~dB}$ in the case of AIN/IDT/AIN/Sapphire heterostructures compared to $17 \mathrm{~dB}$ in the case of the conventional IDT/AIN/Sapphire structure.

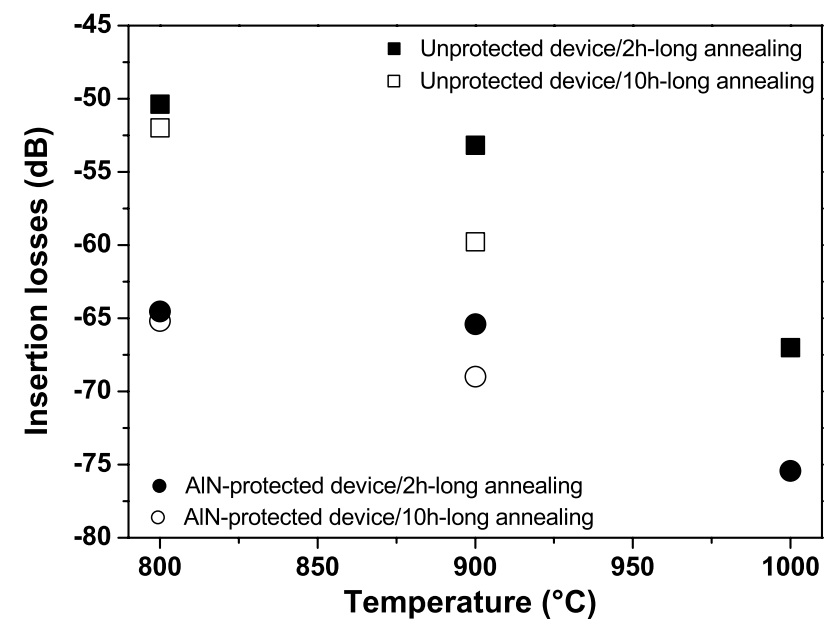

Figure 10. Insertion losses values at room temperature of the unprotected and AlN-protected SAW devices after different annealing steps. 


\section{CONCLUSION}

The stability of AIN/IDT/AIN/Sapphire SAW heterostructures in air at high temperatures $\left(800-1000^{\circ} \mathrm{C}\right)$ has been investigated. It was demonstrated that the AlN protective layer inhibits the agglomeration phenomena of pure platinum electrodes even at $1000^{\circ} \mathrm{C}$. The SAW devices show a promising stability after $12 \mathrm{~h}$ at $800^{\circ} \mathrm{C}$. Longer annealing periods are ongoing to characterize more deeply the devices stability up to $800^{\circ} \mathrm{C}$. At higher temperatures, the SAW device performances are deteriorated by the gradual oxidation of the AlN top layer. The oxidation process dramatically accelerates at $1000^{\circ} \mathrm{C}$ as pores appear inside the AlN overlayer. These pores could be related to the tensile stress undergone by the $\alpha$ $\mathrm{Al}_{2} \mathrm{O}_{3}$ overlayer at each cooling sequence because of the TCE mismatch between $\alpha-\mathrm{Al}_{2} \mathrm{O}_{3}$ and $\mathrm{AlN}$. In summary, the AlN/IDT/AIN/Sapphire SAW heterostructures are very promising for high temperature applications up to $800^{\circ} \mathrm{C}$. For applications at higher temperatures, it would be advantageous to replace the AlN overlayer by an oxide protective layer that would act as an efficient diffusion barrier against oxygen. This oxide layer should be chosen meticulously. Especially, its TCE should be close to the one of AlN.

\section{REFERENCES}

[1] M. Pereira da Cunha, R. J. Lad, T. Moonlight, G. Bernhardt and D.J Frankel, "High temperature stability of langasite surface acoustic wave devices," in Proc. IEEE Ultrasonics Symp., 2008, pp. 205-208.

[2] T. Aubert, J. Bardong, O. Elmazria, G. Bruckner and B. Assouar, "Iridium interdigital transducers for high-temperature surface acoustic wave applications," IEEE Trans. Ultrason. Ferroelectr. Freq. Control, vol. 59, no. 2, pp. 194-197, Feb. 2012.

[3] R. Fachberger, G. Bruckner, G. Knoll, R. Hauser, J. Biniasch and L. Reindl, "Applicability of $\mathrm{LiNbO}_{3}$, langasite and $\mathrm{GaPO}_{4}$ in high temperature SAW sensors operating at radio frequencies," IEEE Trans. Ultrason. Ferroelectr. Freq. Control, vol. 51, no. 11, pp. 1427-1431, Nov. 2004.

[4] M. Peireira da Cunha, R. J. Lad, T. Moonlight, S. Moulzolf, A. Canabal, R. Behanan, P. M. Davulis, D. Frankel, G. Bernhardt, T. Pollard and D. F. McCann, "Recent advances in harsh environment acoustic wave sensors for contemporary applications," in IEEE Sensors Symp. Proc., 2011, pp. 614-617.

[5] H. Seh and H. L. Tuller, "Defects and transport in langasite I: acceptordoped (La3 $\mathrm{Ga}_{5} \mathrm{SiO}_{14}$ )," J. Electroceram., vol. 16, no. 2, pp. 115-125, 2006.

[6] T. Aubert and O. Elmazria, "Stability of langasite regarding SAW applications above $800^{\circ} \mathrm{C}$ in air atmosphere," in Proc. IEEE Ultrasonics Symp., 2012, pp. 2098-2101.

[7] T. Aubert, O. Elmazria, B. Assouar, L. Bouvot, and M. Oudich, "Surface acoustic wave devices based on AIN/Sapphire structure for high temperature applications," Appl. Phys. Lett., vol. 96, art. no. 203503, 2010

[8] C.-M. Lin, T.-T. Yen, V. V. Felmetsger, M. A. Hopcroft, J. H. Kuypers and A. P. Pisano, "Thermally compensated aluminium nitride Lamb wave resonators for high temperature applications," Appl. Phys. Lett., vol. 97, art. no. 083501, 2010 .

[9] G. Bruckner, J. Bardong, R. Fachberger, E. Forsen and D. Eisele, "Investigations of SAW delay lines on c-plane AlN/sapphire at elevated temperatures," in Proc. IEEE Int. Frequency Control Symp., 2010, pp. 499-502.

[10] C. Caliendo and P. M. Latino, "Characterization of Pt/AlN/Pt-based structures for high temperature, microwave electroacoustic devices applications," Thin Solid Films, vol. 519, pp. 6326-6329, 2011.

[11] T. Aubert, O. Elmazria, B. Assouar, E. Blampain, A. Hamdan, D. Genève and S. Weber, "Investigations on AlN/sapphire piezoelectric bilayer structure for high-temperature SAW applications," IEEE Trans. Ultrason. Ferroelectr. Freq. Control, vol. 59, no. 5, pp. 999-1005, May 2012.

[12] T. Aubert, J. Bardong, O. Legrani, O. Elmazria, B. Assouar, G. Bruckner and A. Talbi, "In situ high-temperature characterization of AlN-based surface acoustic wave devices," J. Appl. Phys., vol. 114, art. no. 014505,2013

[13] E. Blampain, O. Elmazria, T. Aubert, B. Assouar and O. Legrani, "AlN/Sapphire: a promising structure for high temperature and high frequency SAW devices," IEEE Sensors J., vol. 13, no. 12, pp. 4607 4612, 2013

[14] R. Salut, A. Claudel, G. Martin, W. Daniau, D. Pique, S. Ballandras, "Fabrication of a $4.4 \mathrm{GHz}$ oscillator using SAW excited on epitaxial AlN grown on a sapphire substrate," in Proc. IEEE Ultrasonics Symp., 2013, pp. 267-270.

[15] T. Aubert, O. Elmazria, B. Assouar, L. Bouvot, M. Hehn, S. Weber, M. Oudich, and D. Geneve, "Behavior of Platinum/Tantalum as interdigital transducers for SAW devices in high-temperature environments," IEEE Trans. Ultrason. Ferroelectr. Freq. Control, vol. 58, no. 3, pp. 603-611, Mar. 2011.

[16] S. L. Firebaugh, K. F. Jensen and M. A. Schmidt, "Investigation of hightemperature degradation of platinum thin films with an in situ resistance measurement apparatus," J. Microelectromech. Syst., vol. 7, no. 1, pp. $128-135,1998$.

[17] J. Chaudhuri, L. Nyakiti, R. G. Lee, Z. Gu, J. H. Edgar, and J. G. Wen, "Thermal oxidation of single crystalline aluminum nitride," Mater. Charact., vol. 58, no. 8-9, pp. 672-679, 2007.

[18] A. D. Katnani and K. I. Papathomas, "Kinetics and initial stages of oxidation of aluminum nitride: thermogravimetric analysis and X-ray photoelectron spectroscopy study," J. Vac. Sci. Technol. A, vol. 5, pp. 1335-1340, 1987.

[19] J. W. Lee, I. Radu and M. Alexe, "Oxidation behavior of AlN substrate at low temperature," J. Mater. Sci.: Mater. Electron., vol. 13, no. 3, pp. 131-137, 2002.

[20] J.J. Campbell and W. R. Jones, "A method for estimating optimal crystal cuts and propagation directions for excitation of piezoelectric surface waves," IEEE Trans. Sonics Ultrason., vol. SU-15, no. 4, pp. 209-217, 1968.

[21] K. Tsubouchi and N. Mikoshiba, "Zero-temperature-coefficient SAW devices on AlN epitaxial films," IEEE Trans. Sonics Ultrason., vol. SU32, no. 5, pp. 634-644, Sep. 1985.

[22] C. Caliendo, "Theoretical and experimental investigation of gigahertzband, temperature-compensated electromechanical coupling configurations based on AIN films," Appl. Phys. Lett., vol. 92, no. 3, art. no. 033505,2008 .

[23] G. Carlotti, G. Gubbiotti, F. S. Hickernell, H. M. Liaw and G. Socino "Comparative study of the elastic properties of polycrystalline aluminium nitride films on silicon by Brillouin light scattering," Thin Solid Films, vol. 310, pp. 34-38, 1997.

[24] C. Deger, E. Born, H. Angerer, O. Ambacher, M. Stutzmann, J Hornsteiner, E. Riha and G. Fischerauer, "Sound velocity of $\mathrm{Al}_{\mathrm{x}} \mathrm{Ga}_{1-\mathrm{x}} \mathrm{N}$ thin films obtained by surface acoustic wave measurements," Appl. Phys. Lett., vol. 72, no. 19, pp. 2400-2402, 1998.

[25] A. V. Sotnikov, H. Schmidt, M. Weihnacht E. P. Smirnova, T. Y. Chemekova and Y. N. Makarov, "Elastic and piezoelectric properties of AlN and $\mathrm{LiAlO}_{2}$ single crystals," IEEE Trans. Ultrason. Ferroelectr. Freq. Control, vol. 57, no. 4, pp. 808-811, Apr. 2010. 